\title{
RESPONSE OF SYSTEMIC PUVA IN VITILIGO - EXPERIENCE WITH 25 CASES IN COMBINED MILITARY HOSPITAL, DHAKA
}

\author{
Karim ATMR ${ }^{1}$, Khan $\mathrm{MAL}^{2}$, Hassan $\mathrm{MS}^{3}, \mathrm{Ahmed}^{4}$, Khan $\mathrm{SI}^{5}, \mathrm{Al}^{-\mathrm{Azad} \mathrm{M}_{\mathrm{MAS}}}{ }^{6}$, Sadeque $\mathrm{SP}^{7}$
}

\begin{abstract}
Introduction: It is a pigmentation disorder in which melanocytes (the cells that make pigment) in the skin are destroyed. As a result, white patches appear in the skin in different parts of the body.
\end{abstract}

Objective: The objective of this study is to see the efficacy of systemic PUVA in the treatment of vitiligo patient.

Methods: This is an prospective longitudinal interventional study, carried out in the depigmented area was assessed according to the department of Dermatology and Venereology, Combined Military Hospital, Dhaka in between the duration of April 2010 to March 2011. Total 25 vitiligo patients based on inclusion criteria like patient with vitiligo affecting more than $5 \%$ body surface area, patient having ivory- white fluorescence on Wood's lamp, patient who was above 15 years of age, patient who had given written consent, patient was not taken any previous treatment etc.

Results: This study showed the therapeutic response of study group after 04 weeks of therapy, 05 (20\%) patients responsed Fair, 15 (60\%) patients responsed Poor and no responsed by 05 $(20 \%)$ patients. Therapeutic response of study group after 08 weeks of therapy showed that 15 (60\%) patients responsed Fair and $10(40 \%)$ patients responsed Poor. It was observed after 12 weeks of therapy that $13(52 \%)$ patients responsed Poor followed by 10 (40\%) patients responsed Fair and $02(08 \%)$ patients responsed well.
Therapeutic response of study group after 16 weeks of therapy was $15(60 \%)$ patients responsed Fair, followed by 06 (24\%) patients responsed Poor and $04(16 \%)$ patients responsed Good. It was showed that after 20 weeks of therapy $13(52 \%)$ patients responsed Fair, followed by 08 (32\%) patients responsed Good, 03 (12\%) patients responsed Poor and 01 (04\%) patients responsed Excellent. It was observed that after 24 weeks of therapy 12 (48\%) patients responsed Good, followed by 08 (32\%) patients responsed Fair, 03 (12\%) patients responsed Poor and 02 (08\%) patients responsed Excellent.

Conclusion: Systemic PUVA for the repigmentation of vitiligo seems to be effective. Study needs large number of patients for longer period of duration for confirmation of results.

Key-words: Systemic PUVA, vitiligo.

\section{Introduction}

Vitiligo is an idiopathic leukoderma often with a progressive course causing destruction of melanocytes ${ }^{1}$. It may be defined as a specific, common, often heritable, acquired pigmentary disorder, characterized by well circumscribed milky white cutaneous macules devoid of identifiable melanocytes $^{2}$. There are certain theories that explain the destruction of melanocytes in the vitiligo lesions. Possible hypothetical mechanisms ${ }^{3,4}$ have been proposed to induce vitiligo are(a) Autoimmunity or immunohypothesis. (b) Neurohumoral factor or neural hypothesis.

1. Maj A T M Rezaul Karim, MBBS, DDV, MCPS, FCPS, Graded Spl in Darmatology, Border Guard Hospital, Dhaka; 2. Col Md Abdul Latif Khan, MBBS, DDV, FCPS. Combined Military Hospital (CMH), Dhaka; 3. Lt Col Md Sayeed Hasan, MBBS, DDV, FCPS, AFMC, Dhaka; 4. Lt Col Moyassaque Ahmed, MBBS, DDV, FCPS, Combined Military Hospital (CMH) Chittagong; 5. Lt Col Shirajul Islam Khan, MBBS, MCPS, DDV, AFMI, Dhaka; 6. Lt Col Md Abdus Samad Al-Azad, MBBS, MCPS, DFM, Asstt Professor, Forensic Medicine, AFMC, Dhaka Cantt; 7. Dr Shayesta Parvin Sadeque, MBBS, DGO, ICMH, Dhaka. 
(c) Autocytoxicity or self destructive hypothesis. (d) Melanocytorrhagy. There are several types of vitiligo. These are- (a) Localized or focal vitiligo. (b) Segmental vitiligo. (c) Acrofacial vitiligo. (d) Universal vitiligo. (e) Mucosal vitiligo (f) Generalized vitiligo. Wood's Lamp examination of vitiliginous macules show chalky white fluorescence. Skin biopsy for histopathological examination reveals absence of melanocytes in vitiliginous macules ${ }^{2}$. There are several options in the treatment of vitiligo. But the most effective and best treatment is the combination of psoralen group of medications or their derivatives with ultraviolet rays. This is known as psoralen and ultraviolet A (PUVA or photochemotherapy) ${ }^{5,6,7,8}$. PUVA is the photochemical interaction between psoralens (P) and ultraviolet A (UVA) 320-400 nm radiation produced by artificial light. Psoralens are phototoxic compounds that enter cells and then absorb photons to produce photochemical reactions that alter the function of cellular constituents. Psoralen can stimulate melanogenesis. This involves the photoconjugation of psoralen to DNA in melanocytes, mitosis, and subsequent proliferation of melanocytes ${ }^{9}$. An increased formation and melanization of melanosomes, an increased transfer of melanosome to keratinocytes and activation and increased synthesis of tyrosine. UVA or sunlight exert profound effect on skin immune system. They primarily effect the function of epidermal keratinocyte and langerhan cells and additionally affects dermal fibroblast, dendritic cells, T-lymphocyte, mast cell and granulocyte ${ }^{2}$. There are some hypothesies about the mechanism of action of PUVA. PUVA causes photoconjugation of psoralen to DNA and subsequent suppression of mitosis of DNA synthesis and cell proliferation. PUVA downregulates certain lymphocyte and antigen-presenting cell functions, influences adhesion molecule expression and diminishes langerhans cell number within the epidermis. PUVA may also affect specific cells such as lymphocytes or polymorphonuclear leukocytes. PUVA therapy may possibly act by an effect on normal or abnormal immune function involving a direct phototoxic effect on lymphocyte in skin infiltrates or on an abnormal immune function. PUVA stimulates melanogenesis, melanocyte proliferation and migration and reconstitute the normal skin colour in more than $50 \%$ of vitiligo patient $^{10}$.

\section{Material and Methods}

This is an prospective longitudinal interventional study, carried out in the depigmented area was assessed according to the department of Dermatology and Venereology, Combined Military Hospital, Dhaka in between the duration of April 2010 to March 2011. Study was included 25 vitiligo patients based on inclusion criteria like patient with vitiligo affecting more than $5 \%$ body surface area, patient having ivory- white fluorescence on Wood's lamp, patient who were above 15 years of age, patient who had given written consent, patient was not taken any previous treatment etc. The exclusion criteria include patient unwilling to give informed consent, pregnant women and lactating mother, history of hypersensitivity with phototherapy and/or psoralen, patient suffering liver disease, kidney disease, thyroid disease and diabetes mellitus.

Treatment procedure: Before inclusion in the study, all the participants were elaborately informed about the natural history and prognosis of their disease, proper application procedures for the phototherapy, possible therapeutic outcomes and adverse effects. So that they can make independent decision about their participation. They were assured of strict privacy and secrecy of information on all occasions and as such necessary measures were taken beforehand. In addition to clinical examination the following investigations has done in all cases- Wood's lamp examination, liver function tests, fasting blood sugar and 2 hours after breakfast, blood urea and serum creatinine, serum calcium level, antinuclear antibody test and thyroid function tests.

Patients were given oral 8-MOP (8-Methoxypsoralen) at a dose of $0.6 \mathrm{mg} / \mathrm{kg}$ body weight two hours before the exposure of UVA. The initial UVA dosages were $1.5 \mathrm{~J} / \mathrm{cm}^{2}$ and gradually increased the dose. Treatments were carried out twice in a week. All patients received 48 sessions of PUVA therapy over whole body with eye protection. Efficacy was evaluated in every follow up visit at 4 weeks interval and finally evaluated at his or her 6th follow up visit. In each patient, the size of rule of nine before treatment. Photographic records were taken before and after treatment. Treatment efficacies will be classified into five groups (designated A-E): 


$\begin{array}{lll}\text { Nil } & \text { Group-A } & 0 \% \\ \text { Poor } & \text { Group-B } & 01-25 \% \text { repigmentation } \\ \text { Fair } & \text { Group-C } & 26-50 \% \text { repigmentation } \\ \text { Good } & \text { Group-D } & 51-75 \% \text { repigmentation } \\ \text { Excellent } & \text { Group-E } & 76-100 \% \text { repigmentation }\end{array}$

The scoring was done on the basis of induced repigmentation in vitiligo spots and the responses in each visit were endorsed in the study protocol. By the end of the therapy, the percentage, score for each patient was evaluated by statistical analysis which.

\section{Results}

A prospective longitudinal interventional study, carried out in the department of Dermatology and Venereology, Combined Military Hospital, Dhaka cantonment, Dhaka to see the efficacy of systemic PUVA in the treatment of Vitiligo.

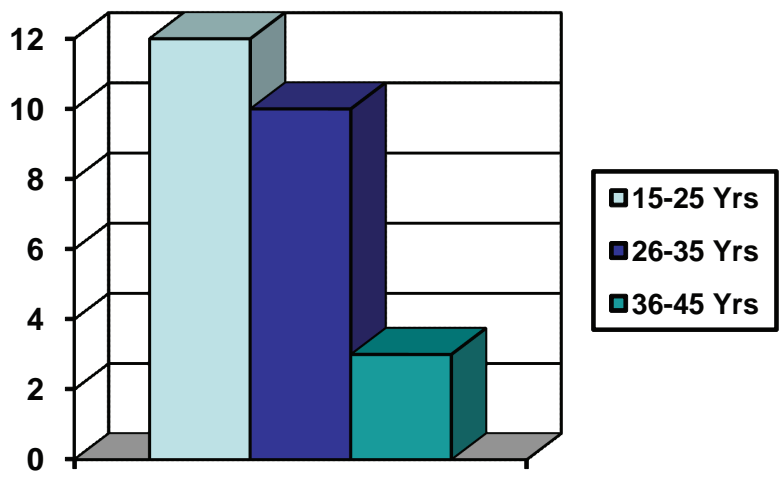

Fig-1: Distribution of the patients by age $(n=25)$.

Figure-1 shows the age distribution of the patients. In study group the patient's age was between 15-45 years and mean age was 28.16 years. The highest number of the participant was between the 15-25 years aged group.

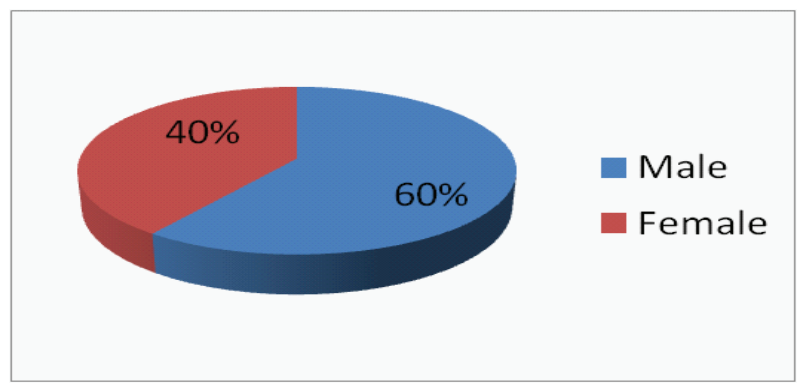

Fig-2: Distribution of sex of the respondents $(n=25)$.

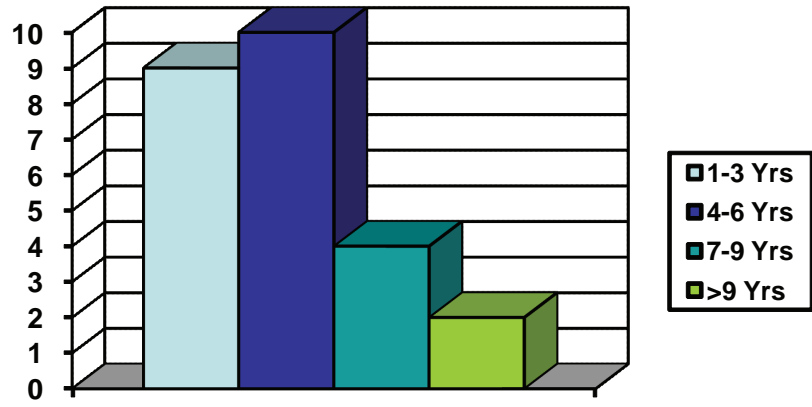

Fig-3: Distributon of the patients by duration of the lesins.

Figure-3 Shows the duration of the lesions of the patients. The range of duration in study group was 02 years to 16 years. Among the 25 cases of study group maximum duration of the lesions were 4-6 Yrs $10(40 \%)$ followed by 1-3 Yrs 09 (36\%), 7-9 Yrs $04(16 \%)$ and $>9$ Yrs 02 (08\%).

Table-I Shows frequency of distribution of the patients in this study as per number of skin lesions. Maximum number of lesions in study group was between 11-20 followed by less than 10 .

Table-I: Distribution of the patients by number of lesions $(n=25)$.

\begin{tabular}{|l|c|c|}
\hline $\begin{array}{l}\text { Number of } \\
\text { lesions }\end{array}$ & $\begin{array}{c}\text { Number of } \\
\text { patients }\end{array}$ & $\begin{array}{c}\text { Percent } \\
(\%)\end{array}$ \\
\hline$<10$ & 06 & $24 \%$ \\
\hline $11-20$ & 12 & $48 \%$ \\
\hline $21-30$ & 04 & $16 \%$ \\
\hline $31-40$ & 03 & $12 \%$ \\
\hline
\end{tabular}

Table-II Shows Therapeutic response of study group after 04 weeks of therapy. $05(20 \%)$ patients responsed Fair-C, $15(60 \%)$ patients responsed Poor-B and no responsed 05 (20\%) patients.

Table-II: Therapeutic response of study group after 04 weeks of therapy.

\begin{tabular}{|l|c|c|}
\hline $\begin{array}{l}\text { Response } \\
\text { (\% repigmentation) }\end{array}$ & $\begin{array}{c}\text { Number of } \\
\text { Patient }\end{array}$ & $\begin{array}{c}\text { Percent } \\
\text { (\%) }\end{array}$ \\
\hline Excellent - E (76-100\%) & 00 & $00 \%$ \\
\hline Good - D (51-75\%) & 00 & $00 \%$ \\
\hline Fair - C (26-50\%) & 05 & $20 \%$ \\
\hline Poor - B (1-25\%) & 15 & $60 \%$ \\
\hline Nil-A ( 0 \%) & 05 & $20 \%$ \\
\hline
\end{tabular}

Table-III Shows Therapeutic response of study group after 08 weeks of therapy. $15(60 \%)$ patients responsed Fair-C and 10 (40\%) patients responsed Poor-B. 
Table-III: Therapeutic response of study group after 08 weeks of therapy.

\begin{tabular}{|l|c|c|}
\hline $\begin{array}{l}\text { Response } \\
\text { (\% repigmentation) }\end{array}$ & $\begin{array}{c}\text { Number of } \\
\text { Patient }\end{array}$ & $\begin{array}{c}\text { Percent } \\
\text { (\%) }\end{array}$ \\
\hline Excellent- E (76-100\%) & 00 & $00 \%$ \\
\hline Good-D (51-75\%) & 00 & $00 \%$ \\
\hline Fair - C (26-50\%) & 15 & $60 \%$ \\
\hline Poor - B (1-25\%) & 10 & $40 \%$ \\
\hline Nil- A ( 0 \%) & 00 & $00 \%$ \\
\hline
\end{tabular}

Table-IV Shows Therapeutic response of study group after 12 weeks of therapy. $13(52 \%)$ patients responsed Poor-B followed by $10(40 \%)$ patients responsed, Fair-C and 02 (08\%) patients responsed Good-D.

Table-IV: Therapeutic response of study group after 12 weeks of therapy.

\begin{tabular}{|l|c|c|}
\hline $\begin{array}{l}\text { Response } \\
\text { (\% repigmentation) }\end{array}$ & $\begin{array}{c}\text { Number of } \\
\text { Patient }\end{array}$ & $\begin{array}{c}\text { Percent } \\
\text { (\%) }\end{array}$ \\
\hline Excellent - E (76-100\%) & 00 & $00 \%$ \\
\hline Good - D (51-75\%) & 02 & $08 \%$ \\
\hline Fair - C (26-50\%) & 10 & $40 \%$ \\
\hline Poor - B (1-25\%) & 13 & $52 \%$ \\
\hline Nil - A (0\%) & 00 & $00 \%$ \\
\hline
\end{tabular}

Table-V Shows Therapeutic response of study group after 16 weeks of therapy.15 (60\%) patients responsed Fair-C followed by $06(24 \%)$ patients responsed Poor-B and 04 (16\%) patients responsed Good-D.

Table-V: Therapeutic response of study group after 16 weeks of therapy.

\begin{tabular}{|l|c|c|}
\hline $\begin{array}{l}\text { Response } \\
\text { (\% repigmentation) }\end{array}$ & $\begin{array}{c}\text { Number of } \\
\text { Patient }\end{array}$ & $\begin{array}{c}\text { Percent } \\
(\%)\end{array}$ \\
\hline Excellent- E (76-100\%) & 00 & $00 \%$ \\
\hline Good - D (51-75\%) & 04 & $16 \%$ \\
\hline Fair - C (26-50\%) & 15 & $60 \%$ \\
\hline Poor - B (1-25\%) & 06 & $24 \%$ \\
\hline Nil - A (0 \%) & 00 & $00 \%$ \\
\hline
\end{tabular}

Table-VI Shows Therapeutic response of study group after 20 weeks of therapy. $13(52 \%)$ patients responsed Fair-C followed by 08 (32\%) patients responsed Good-D, $03(12 \%)$ patients responsed Poor-B and 01 (04\%) patients responsed Excellent-E.

Table-VI: Therapeutic response of study group after 20 weeks of therapy.

\begin{tabular}{|l|c|c|}
\hline $\begin{array}{l}\text { Response } \\
\text { (\% repigmentation) }\end{array}$ & $\begin{array}{c}\text { Number of } \\
\text { Patient }\end{array}$ & $\begin{array}{c}\text { Percent } \\
(\%)\end{array}$ \\
\hline Excellent - E (76-100\%) & 01 & $04 \%$ \\
\hline Good - D (51-75\%) & 08 & $32 \%$ \\
\hline Fair - C (26-50\%) & 13 & $52 \%$ \\
\hline Poor - B (1-25\%) & 03 & $12 \%$ \\
\hline Nil - A (0\%) & 00 & $00 \%$ \\
\hline
\end{tabular}

Table-VII Shows Therapeutic response of study group after 24 weeks of therapy. $12(48 \%)$ patients responsed Good-D followed by $08(32 \%)$ patients responsed Fair-C, 03 (12\%) patients responsed Poor-B and $02(08 \%)$ patients responsed Excellent-E.

Table-VII: Therapeutic response of study group after 24 weeks of therapy.

\begin{tabular}{|l|c|c|}
\hline $\begin{array}{l}\text { Response } \\
\text { (\% repigmentation) }\end{array}$ & $\begin{array}{c}\text { Number of } \\
\text { Patient }\end{array}$ & $\begin{array}{c}\text { Percent } \\
(\%)\end{array}$ \\
\hline Excellent - E (76-100\%) & 02 & $08 \%$ \\
\hline Good - D (51-75\%) & 12 & $48 \%$ \\
\hline Fair - C $(26-50 \%)$ & 08 & $32 \%$ \\
\hline Poor - B (1-25\%) & 03 & $12 \%$ \\
\hline Nil $-\mathrm{A}(0 \%)$ & 00 & $00 \%$ \\
\hline
\end{tabular}

Photographs: Case No-1.

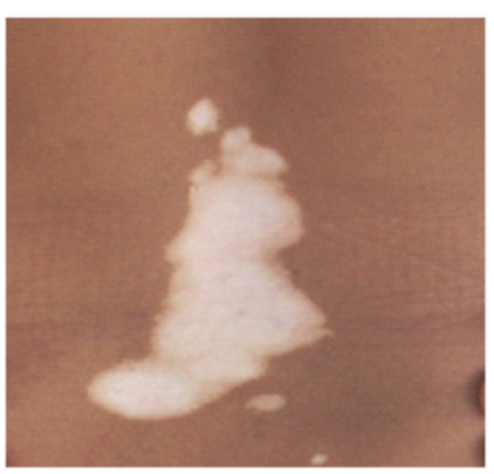

Before treatment

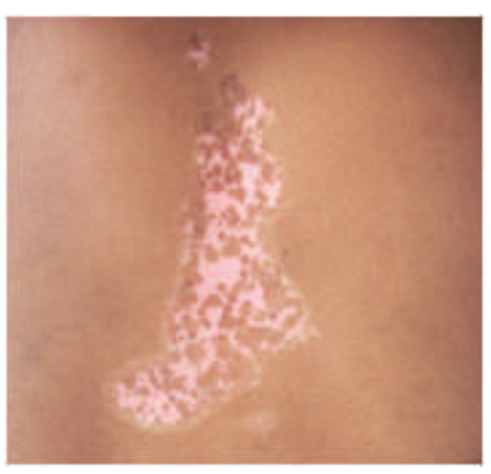

After treatment
Photographs: Case No-2.

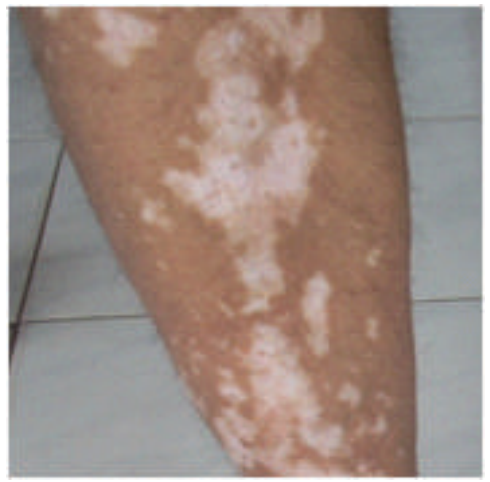

Before treatment

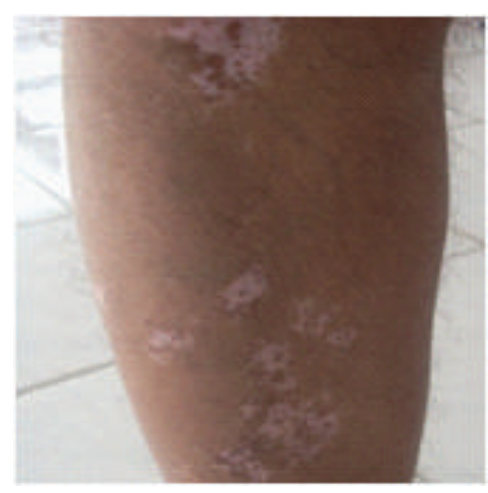

After treatment

\section{Discussion}

Craig et al conducted an open study on 25 patients who were suffering from non-segmental vitiligo with systemic PUVA twice weekly for 48 treatments. They showed $44 \%$ of the patients matched the color of repigmented skin with the color of uninvolved skin in vitiligo ${ }^{10}$. 
Sami et al conducted an open study on 25 patients with generalized vitiligo with systemic PUVA twice weekly for 48 sessions. Peripheral repigmentations were 09 patients $(36 \%)$, follicular repigmentation were 23 patients $(92 \%)$, areas of repigmentation were $23(92 \%)$. The assessment of the color match in comparison with the patients unaffected skin at the end of treatment were 11 patients (44\%). In the remaining 12 patients (48\%), the repigmented areas were noticeably darker than the patients' unaffected skin $^{11}$. Bhatnagars et al conducted a randomized, prospective and open trial study on 25 patients with generalized vitiligo. Twenty five patients were treated with systemic PUVA twice daily for 5.6 months. The mean degree of repigmentation was $54.2 \%{ }^{12}$. S Mahmood et al conducted an open study on 56 patients with non-segmental vitiligo. PUVA treatment was applied on a twice weekly schedule for 48 treatments. $36 \%$ of patients showed $>50 \%$ improvement in body surface affects and complete repigmentation in were $23.6 \%{ }^{13}$. Our study has also indicated that treatment with systemic PUVA is much more effective in initial and also in final stage for reaching complete repigmentation. After 06 months of treatment with systemic PUVA excellent and good response have been achieved in 56\% (14/25) cases which correlates with the results achieved by Craig et al, Sami et al and Bhatnagars et al $\mathrm{a}^{10,11,12}$. Valkova et al conducted a pilot study in 33 Vitiligo paients with systemic PUVA. Erythema, itching and gastrointestinal disturbances occurred with some patients ${ }^{14}$. Wildfang et al reported no actinic keratoses, lentigines or skin cancer in a retrospective study on 59 patients with vitiligo treated with PUVA ${ }^{15}$. Antoniou et al reported no actinic keratoses or skin cancer in 21 patients with vitiligo treated with PUVA followed for up to 07 years $^{16}$. In our study, 05 out of 25 patients $(20 \%)$ had mild to moderate erythema, irritation and pruritus. 02 out of 25 patients $(08 \%)$ noticed of nausea and headache. None of the patients developed skin cancer. No new lesions occurred during the treatment. Our study correlates with the results achieved by Valkova et al and Wildfang et $\mathrm{al}^{14,15}$.

\section{Conclusion}

Systemic PUVA for the repigmentation of vitiligo seems to be effective. Our studies have shown the efficacy of systemic PUVA in the treatment of vitiligo. Study needs large number of patients for longer period of duration for confirmation of results.

\section{References}

1. Volkova S, Trashlieva M, Christova P. Treatment of vitiligo with local Khellin and UVA: Comparison with Systemic PUVA. Clin EXP Dermatol 2004; 29 (2): 180-4.

2. Jean P, Ortonne P, Bahaduran B, Fitzpatrick B, Esher YH. Hypomelanoses and hypermelanoses. In: Iswin M. Frededberg, Arthrur Z, Elisen et al editors. Dermatology in general medicine. sixth edition, Newyork: McGraw-Hill; 839-47.

3. Jane way, Travers CAJ, Walport P. Immunobiology .Newyork, Garland Publishing, 2001.234-9.

4. Taneja A. "Treatment of vitiligo "Journal of Dermatological Treatment 2002;13: 19-25.

5. Harish Badu. The most Effective Treatment of vitiligoPhotochemotherapy: Best to regain . skin color. Jul 6, 2009; 101: $37-45$.

6. Jimbow K. Vitiligo-Therapeutic advances. Dermatol Clin. 1998 Apr ; 16(2) : 399-407.

7. Ermis O, Alpsoy E, Cetin L, Yilaz E. Is the efficacy of psoralen plus ultraviolet $A$ therapy for vitiligo enhanced by concurrent topical calcipotriol ? A placebo-controlled double-blind study.Br J Dermatol 2001; 145(3): 472-5.

8. Wawkrodger DJ, Ormerod AD. Vitiligo. The British Journal of Dermatology 2008; 199(5): 1051-76.

9. Warwick L, Morison. PUVA chemotherapy In: Stephen E. Wolverton, editor. Comprehensive Dermatological drug therapy; W B Saunders Company: 311-25.

10. Craig A, Elmets MD. Repigmentation in Vitiligo. Journal Watch Dermatology. 2007; 34:23-7.

11. Sami SY, Dip D, Roy A. Palmer,Efficacy of Psoralen- UVA Therapy vs NB-UVB Therapy. Arch Dermatol 2007; 143:578-84.

12. Bhatnagar A, Kanwar AJ. Comparison of systemic PUVA and NB-UVB in the treatment of Vitiligo. J Eur Acad Dermatol Venereol 2007; 21(5):638-42.

13. Mahmood BH, Hexsel CL. An update on new and emerging options for the treatment of Vitiligo. Skin Therapy Lette Mar 2008; 13. (2).78-89.

14. Valkova S, Trashlieva M. Treatment of Vitiligo. Journal of British association of Dermatologist 2007;29(2): p180-4.

15. Wildfang, Chuan, Halder, Westerhof and Schallreuter. Late complication of PUVA or NB-UVB Therapy in patients with Vitiligo. Archives of Dermatology December 1998; 134(12): 23-7.

16. Antoniou C, Katsambas A. Guidelines for the treatment of vitiligo. Drugs1992 Apr; 43(4): 490-8. 